
December 1944

\title{
USE OF SEALED TUBES FOR THE PREPARATION OF ACID SOLUTIONS OF SAMPLES FOR ANALYSIS, OR FOR SMALL-SCALE REFINING: PRESSURES OF ACIDS HEATED ABOVE $100^{\circ} \mathrm{C}$
}

\author{
By Charles L. Gordon, William G. Schlecht, and Edward Wichers
}

\section{ABSTRACT}

This paper describes special technics suitable for the use of sealed tubes in treating refractory materials with hydrochloric acid and other acid mixtures at eievated temperatures. Methods for filling, for sealing, and for opening tubes are discussed. The feasibility of reuse of tubes of Pyrex glass is discussed with some observed phenomena of the attack of the glass by the acids. A protecting shell is described together with a method of using solid carbon dioxide to provide the compensating pressures needed to protect the sealed tubes from bursting. The pressures developed on heating hydrochloric acid and mixtures of hydrochloric acid with nitric or perchloric acids were measured in a special gage, which is described.

\section{CONTENTS}

I. Introduction

II. Charging, sealing, and opening the tubes

III. Reuse of the tubes

IV. Protection against excessive internal pressures

V. Design and use of the steel protecting shell

1. Pressures developed by carbon dioxide at elevated temperatures _...

VI. An all-glass (or quartz) pressure gage

VII. Pressures developed by acid mixtures at elevated temperatures...... 467

\section{INTRODUCTION}

The work already reported ${ }^{12}$ on the preparation of refractory materials for analysis involved the technics of the sealed tube, and because of the high pressures encountered, methods for the protection of these tubes against explosions were devised. The pressures developed by the acids used were so great that the tubes, with the exception of those of rather small bore, required protection by an external compensatory pressure.

For the larger-scale solution of refractory materials a heavy-walled 15-by $20-\mathrm{mm}$ Pyrex tube was used and provided with a filling stem of 4-by 8-mm Pyrex tubing, as shown in figure 1. The technic of filling these tubes through the 4 -by 8 -mm stems and subsequently sealing

1 E. Wichers, W. G. Schlecht, and C. L. Gordon, Attack of refractory platiniferous materials by acid mixtures at elevated temperatures, J. Research NBS 33, 363 (1944) RP1614.

2 E. Wichers, W. G. Schlecht, and C. L. Gordon, Preparing refractory oxides, silicates, and ceramic materials, for analysis, by heating with acids in sealed tubes at elevated temperatures, J. Research NBS 33, 451 (1944) RP1621. 
them is the same as for the 4-by 8 -mm experimental tubes used in studying reaction rates.

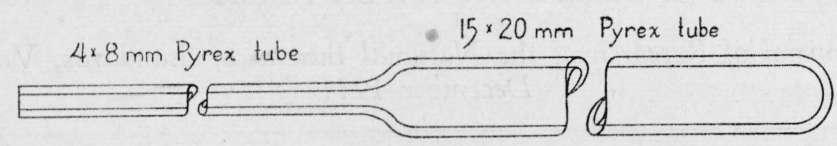

Figure 1.-Sealed tube for solutions.

The volume of the main tube is approximately $1.77 \mathrm{ml} / \mathrm{cm}$. The tube is made twice the length that will accommodate the desired amount of reacting mixture.

\section{CHARGING, SEALING, AND OPENING THE TUBES}

In charging the tubes, the weighed sample is first introduced through the open end or through the stem. If the pieces of the the sample are too large to go through the neck, they should be broken up. If this fails, they must be put into the larger tube before the stem is sealed on. The seal of the stem to the larger tube must always be carefully annealed to avoid excessive strains at this point. If the tube is to be charged with hydrochloric acid, especially if fortified acid is used, it should be cooled in ice. The oxidizing agent, if used, is added next. If this is sodium chlorate, the tube must be chilled enough to freeze the hydrochloric acid and to keep it frozen until the sealing is completed. Sealing may be done by constricting and drawing off a short piece of the tube (or stem) and then working down the sealed tip in the usual way. It can also be done by allowing the open end of the stem to flow together by heating with an oxygen-gas flame and then warming the tube enough to blow out the end to a rounded shape. Good seals made in this way are easier to make and also are stronger than the drawn out seal, unless the latter type of seal is reworked to a hemispherical shape. In either case, care must be taken to be certain that a minute capillary opening is not left, otherwise the gas used to provide the compensating pressure may enter the tube during the heating but be prevented from escaping if the minute orifice is plugged by reaction products. This will leave a dangerously high pressure in the tube when the compensating pressure is released, which is likely to shatter the tube when it is subsequently cut open. ${ }^{3}$

The tube should be placed in the oven horizontally after tipping it to distribute the sample along most of its length.

When the reaction period is completed, the tube can be placed with its lower end in a beaker of warm water. Vapors condensing in the upper end soon wash the glass free of solution. Before opening the tube it is usually best to chill it in a freezing mixture or in solid carbon dioxide. This condenses residual chlorine and diminishes the pressure of nitrogen, which will be present if nitric acid is used as the oxidizing agent. If volatile reaction products are present, chilling the tube before it is opened serves to prevent their escape. When the tube is well chilled the end is cut open, whereupon the tube is inverted in a beaker containing water or whatever liquid may be chosen to dilute

3 Any type seal can be tested for a capillary leakage by standing the carefully wiped tube upside down over a small piece of litmus paper. If the acid mixture is hydrochloric acid with nitric acid, sodium chlorate, or other oxidant that reacts with the hydrogen chloride and develops a pressure at room temperature, leakage will be apparent by wetting the paper and giving it an acid reaction. Other mixtures that do not develop pressure can be warmed slightly while in the described position. 
the concentrated solution of the sample as it melts and runs down the tube.

In opening tubes that contain an excess of oxidant, especially in the form of chlorine that has been frozen, the rate of thawing must be controlled. If the upper sealed end of the inverted tube warms before the lower end, the vaporization of the chlorine will cause explosive expulsion of the still frozen solution below it. The introduction of a stream of warm distilled water through the lower end and directed at the frozen solution will melt the mass from the bottom to the top. The vaporization of the chlorine will then take place at an even rate with no obstruction to develop pressure.

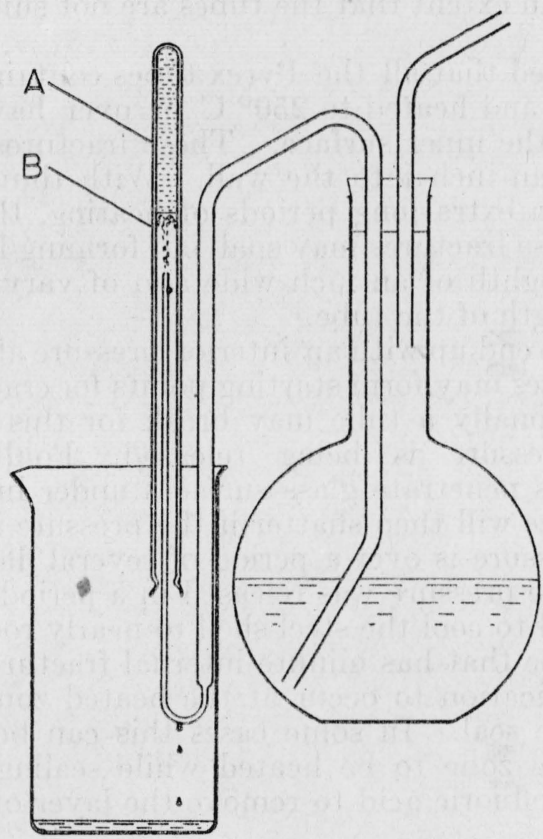

Figure 2.-Method of rinsing solutions from frozen tubes after reaction.

$A$, Frozen solution containing liquid chlorine; $B$, warm wash solution.

A wash bottle equipped with a special nozzle of thin-walled tubing of $2-\mathrm{mm}$ bore ( 2 by $3 \mathrm{~mm}$ ) in the form of an elongated $U$ is an effective means of melting and washing the reaction tube. The frozen tube is inverted over the U, (fig. 2) and into a tall beaker. As melting takes place, the tube is lowered slowly down the $U$ until the wash liquid cleans all the solution out of the tube.

If there are no volatile end products other than the reactants used to effect the solution, the tube may be opened by heating the end of the tube with a fine flame until a small area gives way and lets the excess internal pressure (or the deficient pressure) blow a small hole through it. Continued heating will cause the glass to flow together and blow out in an orifice, too small to be of use for the removal of solutions, and this phenomenon will repeat itself. Then, while the end of the tube is soft, the flame is held momentarily against the glass below the seal, thereby blowing out a large thin bubble. Heating 
the upper portion of this bubble causes it to collapse and fuse into a funnel-shaped cup around the end of the tube with no particles of glass broken off to contaminate the sample. This technic is especially desirable when preparing solutions of materials in which solid residues of silica, titania, etc. are to be determined.

\section{REUSE OF THE TUBES}

If the emptied tubes are to be used a second time, they should be dried and examined carefully. The inner surfaces are usually damaged ${ }^{4}$ by exposure to the acid mixture at high temperature and pressure to such an extent that the tubes are not suitable for repeated use.

It has been noted that all the Pyrex tubes containing hydrochloric acid and chlorine and heated to $250^{\circ} \mathrm{C}$ or over have shown signs of fine fractures on the inner surface. These fractures penetrate about a thousandth of an inch into the wall. With thin-walled tubing of large diameter, on extra long periods of heating, the glass layer between pairs of these fractures may spall off, forming long thin splinters as much as one-eighth of an inch wide and of varying lengths up to the full inside length of the tube.

With tubes that end up with an interior pressure above atmospheric, these little fractures may form starting points for cracks going through the wall. Occasionally a tube may break for this reason while the compensating pressure is being released. Poulter and Wilson ${ }^{5}$ found that liquids penetrate glass surfaces under high pressures and that such a surface will then shatter if the pressure is released, unless the release of pressure is over a period of several days. In the work described here, the pressure was released in a period of about 2 hours (the time required to cool the steel shell to nearly room temperature).

Resealing a tube that has minute internal fractures causes bubbles and some devitrification to occur at the heated zone with great loss of strength of the seal. In some cases this can be prevented if all the surface in the zone to be heated while sealing is treated sufficiently with hydrofluoric acid to remove the layer of glass containing the fractures.

\section{PROTECTION AGAINST EXCESSIVE INTERNAL PRESSURES}

In estimating the probable bursting pressures of tubes, the round figure of $10,000 \mathrm{lb} / \mathrm{in}^{2}{ }^{2}$ can be used as the tensile strength of glass, if the variability of the strength of glass is kept in mind. The presence of strains and of imperfections in the glass, especially at the surfaces, greatly decreases its strength. If internal and external pressures cannot be balanced, it is better to have the external pressure greater because the outside surface is the more likely to be scratched during the operations prior to heating the tube. An approximate formula for calculating the bursting pressure, $A$, in $\mathrm{lb} / \mathrm{in}^{2}{ }^{2}$ of annealed cylindrical glass tubes with well-rounded ends is $A=(2 W / D) 10,000$, in which $W$ is the wall thickness and $D$ is the

\footnotetext{
${ }^{4}$ For most purposes the contamination of the solution resulting from this damage is negligible. For the amount of glass dissolved, see section IV of RP1621.

8 T. C. Poulter and R. O. Wilson, Phys. Rev. 40, 877-80 (1932).
} 
internal diameter. Thus, the pressure which a well-made tube of $15-\mathrm{mm}$ bore and $2.5-\mathrm{mm}$ wall thickness may be expected to withstand is over $3,000 \mathrm{lb} / \mathrm{in} .{ }^{2}$. Some of the tubes of this size used in our experimental work have withstood such pressures. Because of the variable strength of glass, however, it is desirable to use a large factor of safety. The recommended conditions as to strength and quantity of hydrochloric acid will not produce pressures in excess of $4,000 \mathrm{lb} /$ in. $^{2}$ at $300^{\circ} \mathrm{C}$. It will be seen that, as the diameter of the tubing is decreased, a point is soon reached where external compensating pressure is not needed, especially if an occasional failure, caused by some defect in the glass, can be tolerated. For operations on a micro-analytical scale, C. P. Saylor, of this Bureau, has found the use of capillary tubes (preferably of quartz) of approximately $1-\mathrm{mm}$ bore and wall thickness very satisfactory.

The bursting pressures of samples of the actual tubes to be used and with seals made by the person using them can be conveniently determined by the method described by Gordon. ${ }^{6}$ He used the pres-
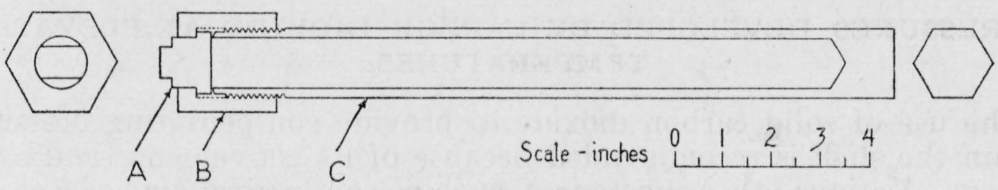

FIGURE 3.-Steel shell for protection of tube.

$A$, Steel head for pressing copper gasket onto knife edge; $B$, graphitic steel nut; $C, 13 / 8$-in. hexagonal steel bar, bored out to a diameter of 1 in. threaded for a cap at one end and with a machined knife edge.

sures generated by a given specific volume (when completely vaporized) of water to correlate bursting at an observed temperature with the pressure developed inside the tube up to the instant of bursting.

\section{DESIGN AND USE OF THE STEEL PROTECTING SHELL}

The design and dimensions of an easily constructed steel protecting

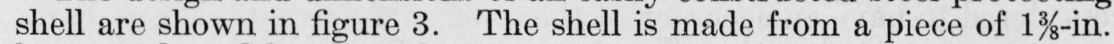
hexagonal steel bar, bored out to a diameter of 1 in. and to within a $1 / 2$ in. of the closed end. The open end is threaded (leaving a uniform $1 / 8$-in. wall thickness uncut) to receive a heavy steel cap, and the rim is carefully machined to a knife edge of about $120^{\circ}$. A disk of soft copper, placed in a recess in the cap, seats against the knife edge and thus provides an effective seal when the cap is screwed on with moderate pressure. The cap is preferably made in two parts, the threaded portion of graphitic steel which will not gall or freeze when screwed on to the ordinary steel, and an ordinary steel insert to bear the copper disk against the knife edge. If the cap is made of the same steel as the shell, the threads are coated with graphite (Aquadag is satisfactory) to keep the threads from freezing.

In the bottom of the shell, which is about 4 inches longer than the tube it is to contain, is put enough calcium carbonate to neutralize all the acid in the tube in the unexpected event of its breaking. The possibility of corrosion of the steel and of dangerously high pressures of hydrogen within the shell are thus avoided. It is desirable to

\footnotetext{
${ }^{6} \mathrm{C} . \mathrm{L}$. Gordon, Modification of the Carius combustion tube to minimize losses by explosion; Pressures attained on heating nitric acid to $300^{\circ} \mathrm{C}$, J. Research NBS 30,107 (1943) RP1521.
} 
wrap the glass tube in a little asbestos yarn to keep it out of contact with the wall of the shell. After the tube is slipped into the shell, solid carbon dioxide is added in an amount calculated to give the desired pressure at the operating temperature. Then the cap is quickly screwed on. After the shell comes to room temperature, it can be tested for tightness by immersing it in water. If the knifeedge is flawless, a few trials will soon indicate how tightly the cap must be screwed on to make a good seal. Seals that do not leak at room temperature are not likely to leak at the higher temperatures, even though the pressure becomes considerably higher.

The shell should be tilted gently a few times to distribute the sample within the tube and then laid horizontally in an oven, which can be kept within a few degrees of the desired temperature. ${ }^{7}$ When the heating period is over, the shell is allowed to cool to room temperature before unscrewing the cap to release the carbon dioxide. If inspection shows that the sample has not been completely attacked, the tube can be returned to the shell for further heating.

\section{PRESSURES DEVELOPED BY CARBON DIOXIDE AT ELEVATED TEMPERATURES}

The use of solid carbon dioxide to provide compensating pressure within the shell is recommended because of its convenience and simplicity. Various other substances, such as compressed air, ${ }^{8}$ or water, ${ }^{9}$ can of course be used. Although the pressure-temperature curves of carbon dioxide, for various densities, do not match the vapor-pressure curves of hydrochloric acid very closely, they do so more nearly than the pressure temperature curves of air or the vapor-pressure curve of water. In figure 4 are shown ranges of pressures observed in a tube half-full of a mixture of hydrochloric and nitric acids, the vapor pressure curve of water over the same range, and the calculated pressuretemperature lines for two densities of carbon dioxide. The carbon dioxide lines are drawn on the basis of extrapolations by C. S. Cragoe, of this Bureau, of observations by Michels-Veraart. ${ }^{10}$ The values are considered to have an accuracy of the order of 1 percent. These data can be interrelated with sufficient accuracy for the present purpose by the equation:

$$
\rho=\frac{P-750}{53.8 t}+0.060
$$

for the range $t=250^{\circ}$ to $300^{\circ} \mathrm{C}, P=2,200$ to $5,900 \mathrm{lb} / \mathrm{in}^{2}$.

$\rho=\operatorname{grams}$ of $\mathrm{CO}_{2}$ to use per cubic centimeter to produce the desired pressure.

$P=$ protecting pressure desired, pounds per square inch.

$t=$ temperature degree centigrade.

It will be seen that densities of carbon dioxide required to provide a compensating pressure nearly equal to that of the acid mixture at

\footnotetext{
? In the absence of a suitable oven the shell itself can be made into a furnace by wrapping it with a layer of asbestos paper and then with a coil of resistance wire. The proper temperature can be maintained by the use of a thermocouple soldered to the shell near its middle, with suitable additional equipment, as a thermostatting device.

statting device. peratures, NBS Tech. News Bul. 284, p. 108 (December 1940).

9 L. A. Greenberg, Bomb furnace for Carius digestion, Ind. Ėng. Chem., Anal. Ed. 18, 308 (1944).

$10 \mathrm{C}$. A. M. Michels-Veraart, Some physical properties of compressed carbon dioxide. Thesis, University of Amsterdam, 1937.
} 
the operating temperature involve some excess external pressure at room temperature. This difference need not exceed $1,000 \mathrm{lb} / \mathrm{in}^{2}$. This is not excessive, except for very large tubes, especially since the glass tubes are usually more resistant to crushing loads than bursting loads. Water is far less desirable as a means of providing the compensating pressures not only because of the nature of its vapor-pressure curve (see fig. 4), but also because of its corrosive effect on glass. No doubt some other substance, or mixture, could be found

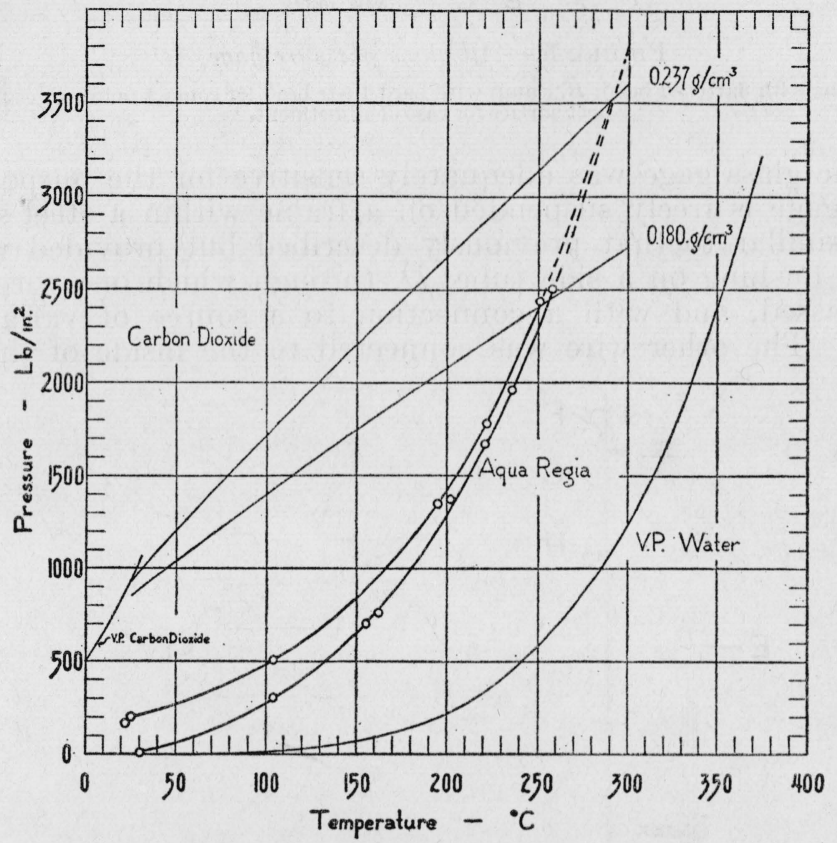

Figure 4.-Pressures developed by $5 \mathrm{ml}$ of aqua regia.

A mixture of 20 volumes of hydrochloric acid, 36 weight-percent of $\mathrm{HCl}$, and 1 volume of nitric acid, 91 weight-percent $\mathrm{HNO}_{3}$ at constant volume on heating. Pressures developed by carbon dioxide and water are given for comparison.

to balance the pressure within the sealed tube more closely than carbon dioxide, if it were necessary to do so.

A simple way to test the steel shell for leaks during a period of heating is to weigh it before and after heating.

\section{AN ALL-GLASS (OR QUARTZ) PRESSURE GAGE}

To measure the pressures developed by hydrochloric acid and other acids at high temperatures, a gage was constructed. Its design was based on a suggestion made by L. B. Tuckerman, of this Bureau. It is shown in figure 5. It is essentially a moderately long $U$-tube, made of quartz or Pyrex glass (both were used) with the bend flattened somewhat to increase the sensitivity to changes in pressure, which occur when the temperature of the acid mixture sealed in the gage is changed. 
To determine its sensitivity, one of the gages was attached to a mercury manometer. A pressure difference of about $7 \mathrm{~cm}$ of $\mathrm{Hg}$ (about $1 \mathrm{lb} / \mathrm{in}^{2}{ }^{2}$ ) was required to reclose the contact after the circuit was just broken. The sensitivity of the Bourdon gage used in the measurements of pressure to be reported was between 5 and $10 \mathrm{lb} / \mathrm{in}^{2}{ }^{2}$

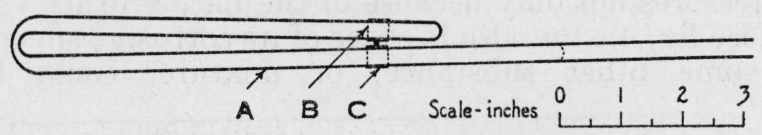

Figure 5.-All glass pressure gage.

$A$, Glass U-tube with flattened bend; $B$, clamp with hard Pt-Ir bead for contact point; $C$, clamp with $\mathrm{Pt}$ sheet surface for ease of adjustment.

Hence the glass gage was adequately sensitive for the purpose. In use, the gage is freely suspended on a frame within a steel shell, $A$ (fig. 6), similar to that previously described but provided with an insulated bushing on a side tube, $D$, through which one wire of the circuit passed, and with a connection to a source of variable gas pressure. The other wire was connected to the inside of the shell.

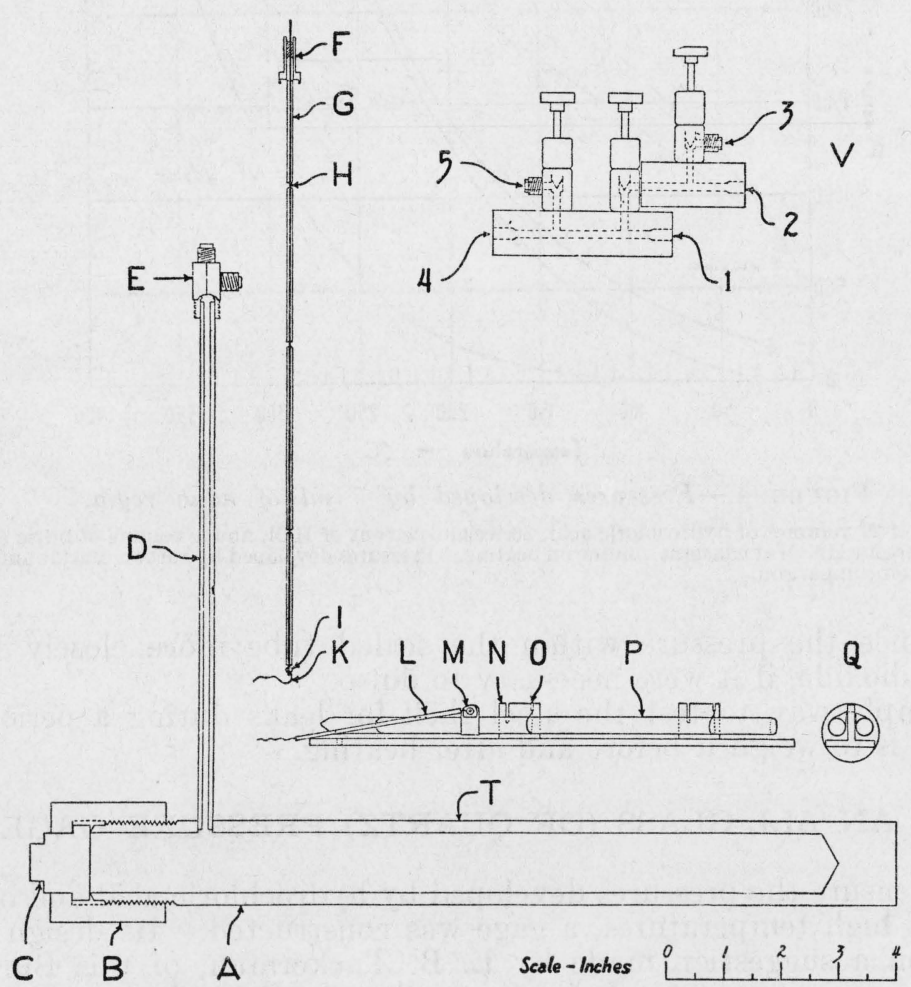

Figdre 6.-Apparatus for measuring pressures developed on heating acids.

$A$ to $K$, Steel shell and insulated connection; $L$ to $Q$, glass gage and supporting frame; $V$, valve system.

Outside the oven in which the shell was heated the circuit was completed through a small source of power and a sensitive milliammeter. The meter served only as an off-and-on indicator but usually gave preliminary warning by flickering when the circuit was about to be 
broken. The temperature of the system was measured by means of a copper-constantan couple hard-soldered to the outside of the shell (at $T$ ) and connected to a student-type potentiometer.

During the pressure determinations the gage was suspended as shown in figure $6, L$ to $Q$, on a steel frame, $N$, by fine platinum-wire loops, $O$. The contacts clamped on the arms of the gage had fine platinum wires attached to make the connections to the electric circuits. One wire was protected by an insulating sleeve, $L$, to prevent grounding and a consequent short-circuit. The suspended gage was slid into the steel shell (fig. $6, A$ ) with the $U$ horizontal, so that the whole assembly was well back of the side tube.

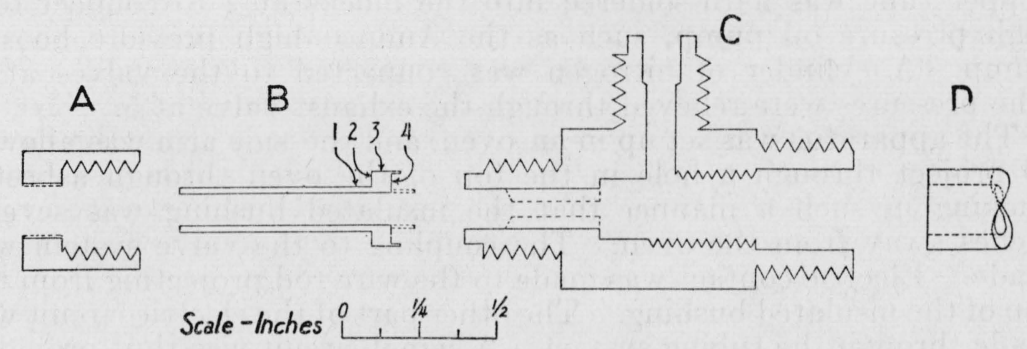

Figure 7.-Construction of insulated bushing.

$A$, Threaded collar; $B$, insulated tube; $C$, connection to auxiliary pressure; $D$, connection to steel shell.

The insulated bushing was made from parts of a needle valve and connector as shown in figure 7 . The threaded collar of the female part of the connector was reamed out to $11 / 64$-in., as shown at $A$. The steel section of the female part of the connector had the tubular center projection removed, as at $B$. The valve seat was removed by reboring the through-hole of the valve to $1 / 8$ in. This part of the valve was placed over the tube $D$ and hard-soldered to it. A fine iron rod of length to just protrude into the autoclave when inserted through the tube $D$ was hard-soldered into the steel part, $B$. Porcelain or thin glass insulators were slid over the wire and a fine connecting wire was hard-soldered to the exposed lower end. The bead of solder served to keep the insulators in place.

Insulation was obtained by use of cardboard and a special packing compound made by beating two white facial tissues into a solution of 6 to $7 \mathrm{~g}$ of zinc chloride in $100 \mathrm{~g}$ of water. The insulation was packed in the following manner: Referring to $B$ (fig. 7 ), a small cardboard collar was placed around the shaft at 1, a small toroid of packing compound (rolled out and slightly blotted) was laid around the shaft at 2, a collar of cardboard was placed around the rim 3, and the threaded cap $A$ was carefully pushed onto the shaft. Finally, a toroid of packing compound was laid in the connector seat 4 and around the insulated rod.

When the assembly was screwed into the valve base, the flexible wire attached to the bottom of the insulated iron rod would often coil up, but it could be pulled out straight so that a connection with the insulated wire from the gage could be made outside the autoclave. This connection was wrapped in thin asbestos paper and then tucked 
into the free space at the end of the shell. The other wire from the gage was hard-soldered to the center of the copper disk gasket, and was also tucked in the free space. The cap was then screwed tightly onto the copper gasket.

The side arm of the bushing was connected by means of a packed union to $1 / 8$-in. copper tubing connecting through a valve system (shown at $V$, fig. 6) to the auxiliary pressure apparatus (not shown). The valve system was made by boring and threading two brass blocks so as to mount three valves as shown. The copper tube from the autoclave was hard-soldered into the blocks at 1 . A copper tube connecting to a Bourdon gage was hard-soldered into the blocks at 4 . Another copper tube was hard-soldered into the blocks at 2 to connect to a high pressure oil pump, such as the Aminco high pressure booster pump. A cylinder of nitrogen was connected to the valves at 3 . The pressures were relieved through the exhaust valve at 5 .

The apparatus was set up in an oven, and the side arm was allowed to project through a hole in the top of the oven through asbestos packing in such a manner that the insulated bushing was several inches away from the oven. The coupling to the valve system was made. Electric contact was made to the wire rod projecting from the top of the insulated bushing. The other part of the electric circuit was made through the tubing system. A signal circuit was thus provided on connecting a battery and millivoltmeter in series with these contacts.

In use, the temperature of the apparatus was raised, and as the signal circuit was broken the pressure in the apparatus was increased by admission of nitrogen from the tank by opening the valve at 3 and then bleeding the gas to the apparatus through the valve at 1. When the pressure required was greater than that delivered by the tank, the gas chamber of the oil pump was allowed to fill, and the valve at 3 was then closed. The valve at 1 was opened, and the pump was operated to raise the pressure to the desired value. Then closing the valve at 1 left only the steel shell and the gage connected. While cooling the apparatus, with consequent lowering of the pressure, the gas in the steel shell was released by opening the valve at 5 .

To begin a series of measurements, the glass or quartz gage, which had a capacity of $11.7 \mathrm{ml}$, was charged with $5 \mathrm{ml}$ of the acid to be studied and sealed without removing the air in the unfilled part. Contacts on the gage were adjusted at room temperature and the gage was placed in the steel shell, which in turn was put in the oven. The temperature of the oven was raised stepwise and held constant at each step until the gage came to a steady balance with the adjusted external pressure. After reaching the highest temperature at which readings were to be made, the temperature was lowered by steps to the starting point. In the measurements on acid mixtures, reactions which occurred changed the composition of the system, hence the temperature-pressure curve did not retrace itself exactly, but closely enough to indicate whether any substantial displacement might have occurred in the gage. Repeated observations at a selected temperature were constant within the sensitivity of the Bourdon gage (5 to $10 \mathrm{lb} / \mathrm{in}^{2}{ }^{2}$. 


\section{PRESSURES DEVELOPED BY ACID MIXTURES AT ELEVATED TEMPERATURES}

In order to fix at least approximately the compensating pressures that should be provided in the steel protecting shell used in the experimental work on refractory materials, ${ }^{11}$ it was necessary to know the pressures developed by hydrochloric acid and its mixtures with suitable oxidizing agents in the temperature range over which the experiments were conducted. Since no such data appeared to be available, measurements were made of nine systems, as follows: Hydrochloric acid of 3 strengths, 23, 36, and 48 weight-percent of $\mathrm{HCl}$; a mixture of 20 volumes of hydrochloric acid (36 weight-percent of $\mathrm{HCl}$ ) with one volume of fuming nitric acid (91 weight-percent of $\mathrm{HNO}_{3}$ ); a mixture of 10 volumes of hydrochloric acid (36 weight-percent of $\mathrm{HCl}$ ) with 1 volume of perchloric acid (60 weight-percent of $\mathrm{HClO}_{4}$ ); hydriodic acid ( 56 weight-percent of $\mathrm{HI}$ ) ; and three different amounts of fuming nitric acid (91 weight-percent of $\mathrm{HNO}_{3}$ ). The data on fuming nitric acid were given in a previous paper by C. L. Gordon. ${ }^{12}$

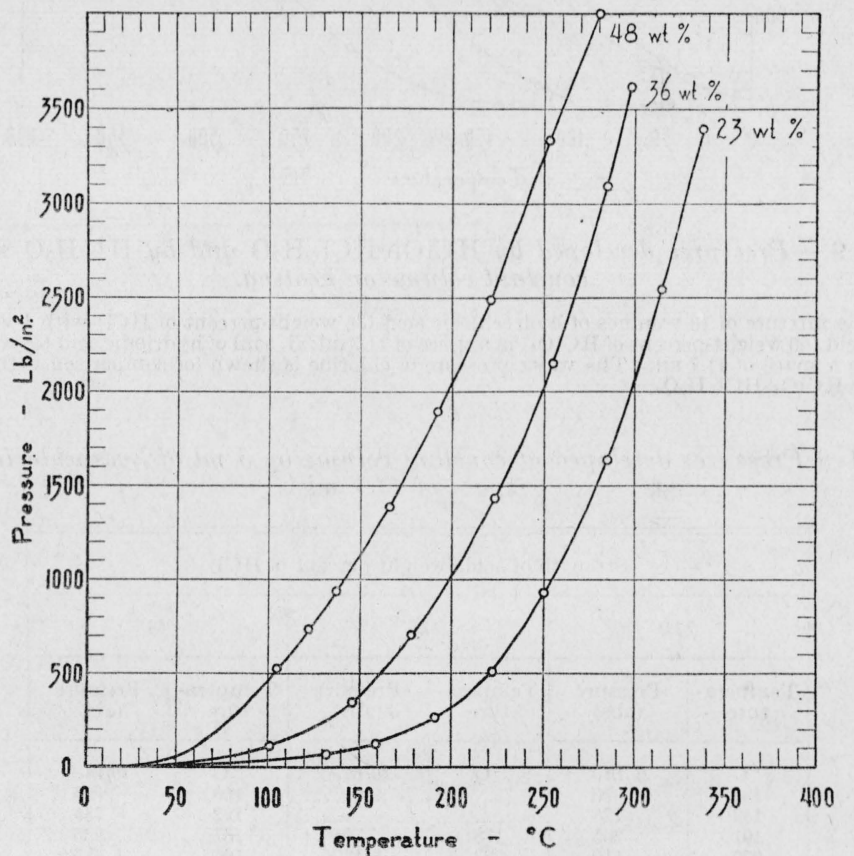

Figure 8.-Pressures developed by hydrogen-chloride solutions of various strengths at constant volume of heating.

$5 \mathrm{ml}$ of acid solution in $11.7-\mathrm{ml}$ space.

The observations on hydrochloric acid are given in table 1 and are shown in figure 8; those on the two mixtures are given in tables 2 and 3 and shown in figures 4 and 9 , respectively. The observations on hydriodic acid are given in table 4 and included in figure 9.

11 See footnotes 1 and 2.
12 See footnote 5 . 


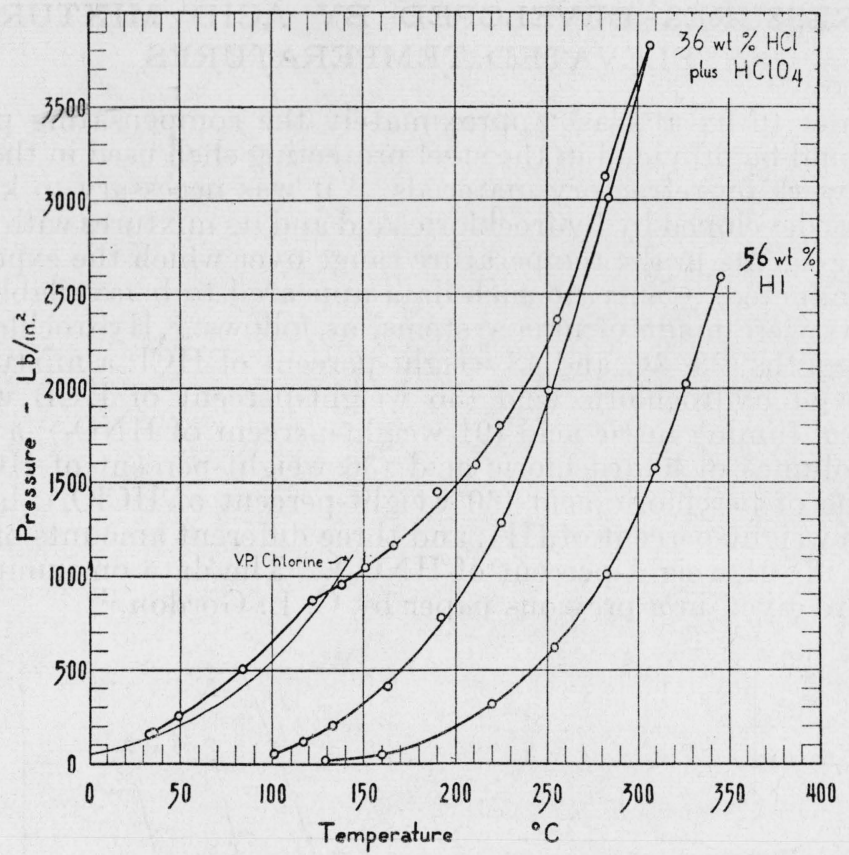

Figure 9.-Pressures developed by $\mathrm{HClO}_{4}-\mathrm{HCl}-\mathrm{H}_{2} \mathrm{O}$ and by $\mathrm{HI}-\mathrm{H}_{2} \mathrm{O}$ mixtures at constant volume on heating.

$A, 5 \mathrm{ml}$ of a mixture of 10 volumes of hydrochloric acid (36 weight-percent of $\mathrm{HCl}$ ) with 1 volume of perchloric acid ( 60 weight-percent of $\mathrm{HClO}_{4}$ ) in a space of $11.7 \mathrm{ml} ; B, 5 \mathrm{ml}$ of hydriodic acid (56 weight-percent of $\mathrm{HI}$ ) in a space of $11.7 \mathrm{ml}$. The vapor pressure of chlorine is shown for comparison with the product curve for $\mathrm{HClO}_{4}-\mathrm{HCl}-\mathrm{H}_{2} \mathrm{O}$.

TABLE 1.-Pressures developed at constant volume by $5 \mathrm{ml}$ of hydrochloric acid in a space of $11.7 \mathrm{ml}$

\begin{tabular}{|c|c|c|c|c|c|}
\hline \multicolumn{6}{|c|}{ Strength of acid (weight-percent of $\mathrm{HCl}$ ) } \\
\hline \multicolumn{2}{|c|}{22.9} & \multicolumn{2}{|c|}{36} & \multicolumn{2}{|c|}{48} \\
\hline $\begin{array}{c}\text { Tempera- } \\
\text { ture }\end{array}$ & $\begin{array}{l}\text { Pressure } \\
\text { (abs) }\end{array}$ & $\begin{array}{l}\text { Tempera- } \\
\text { ture }\end{array}$ & $\begin{array}{l}\text { Pressure } \\
\text { (abs) }\end{array}$ & $\begin{array}{c}\text { Tempera- } \\
\text { ture }\end{array}$ & $\begin{array}{c}\text { Pressure } \\
\text { (abs) }\end{array}$ \\
\hline $\begin{array}{l}{ }^{\circ} C \\
132 \\
159 \\
191 \\
220 \\
250 \\
285 \\
315 \\
338\end{array}$ & $\begin{array}{r}\text { lb/in. } .^{2} \\
70 \\
125 \\
265 \\
510 \\
920 \\
1,640 \\
2,550 \\
3,400\end{array}$ & \begin{tabular}{l}
${ }^{\circ} \mathrm{C}$ \\
\hdashline 178 \\
223 \\
255 \\
285 \\
298
\end{tabular} & $\begin{array}{r}l b / \text { in }^{2} \\
705 \\
1,430 \\
2,150 \\
3,095 \\
3,615\end{array}$ & $\begin{array}{l}{ }^{\circ} C \\
105 \\
122 \\
137 \\
166 \\
192 \\
221 \\
253 \\
270\end{array}$ & $\begin{array}{r}l b / \text { in } .2 \\
525 \\
735 \\
935 \\
1,385 \\
1,895 \\
2,490 \\
3,335 \\
3,995\end{array}$ \\
\hline
\end{tabular}


TABLE 2.-Pressures developed at constant volume by $5 \mathrm{ml}$ of aqua regia made with 20 volumes of hydrochloric acid ( 36 weight-percent of $\mathrm{HCl}$ ) plus 1 volume of fuming nitric acid (91 weight-percent of $\mathrm{HNO}_{3}$ )

\begin{tabular}{|c|c|c|c|}
\hline \multicolumn{2}{|c|}{ First heating } & \multicolumn{2}{|c|}{$\begin{array}{l}\text { Subsequent heatings after } \\
\text { heating to about } 250^{\circ} \mathrm{C}\end{array}$} \\
\hline Temperature & Pressure (abs) & Temperature & Pressure (abs) \\
\hline $\begin{array}{r}{ }^{\circ} C \\
25 \\
106 \\
155 \\
162 \\
202 \\
221 \\
236 \\
258\end{array}$ & $\begin{array}{r}l b / \text { in }^{2} .^{2} \\
10 \\
305 \\
705 \\
765 \\
1,375 \\
1,670 \\
1,960 \\
\approx 2,505\end{array}$ & $\begin{array}{r}{ }^{\circ} C \\
22 \\
25 \\
104 \\
195 \\
222 \\
251 \\
\cdots- \\
--\end{array}$ & $\begin{array}{r}\text { lb/in. } .^{2} \\
165 \\
200 \\
508 \\
1,350 \\
1,780 \\
2,440 \\
\hdashline . . .\end{array}$ \\
\hline
\end{tabular}

- Final pressure established after heating at $258^{\circ} \mathrm{C}$ for a total of about 5 hours.

TABLE 3.-Pressures developed at constant volume by $5 \mathrm{mi}$ of hydrochioric acid (36 weight-percent of $\mathrm{HCl}$ ) plus $0.5 \mathrm{ml}$ of perchloric acid solution (60 weight-percent of $\mathrm{HClO}_{4}$ ) in a space of $11.7 \mathrm{ml}$

\begin{tabular}{|c|c|c|c|}
\hline \multicolumn{2}{|c|}{ First heating } & \multicolumn{2}{|c|}{$\begin{array}{l}\text { Cooling and subsequent } \\
\text { heatings }\end{array}$} \\
\hline Temperature & Pressure (abs) & Temperature & Pressure (abs) \\
\hline $\begin{array}{c}{ }^{\circ} \mathrm{C} \\
101 \\
117 \\
133 \\
163 \\
191 \\
225 \\
251 \\
284 \\
307\end{array}$ & $\begin{array}{r}\text { lb/in. } .^{2} \\
55 \\
120 \\
205 \\
415 \\
780 \\
1,285 \\
1,985 \\
3,010 \\
\mathrm{a} 3,825\end{array}$ & $\begin{array}{c}{ }^{\circ} C \\
282 \\
256 \\
224 \\
211 \\
190 \\
166 \\
151 \\
138 \\
122 \\
84 \\
49 \\
35 \\
33\end{array}$ & $\begin{array}{r}l b / \text { in } .^{2} \\
3,125 \\
2,365 \\
1,800 \\
1,595 \\
1,450 \\
1,165 \\
1,045 \\
955 \\
870 \\
505 \\
255 \\
165 \\
155\end{array}$ \\
\hline
\end{tabular}

s $3,825 \mathrm{lb} /$ in. ${ }^{2}$ was the equilibrium pressure established after being maintained at $307^{\circ}$ for $16 \mathrm{hr}$. A total rise of $10 \mathrm{lb} / \mathrm{in}^{2}$ was noted during this period.

TABLE 4.-Pressures developed at constant volume by $5 \mathrm{ml}$ of hydriodic acid (56 weight-percent of $\mathrm{HI}$ ) in a space of $11.7 \mathrm{ml}$

\begin{tabular}{|c|r|}
\hline $\begin{array}{c}\text { Tempera- } \\
\text { ture }\end{array}$ & $\begin{array}{c}\text { Pressure } \\
\text { (abs) }\end{array}$ \\
\hline${ }^{\circ} C$ & lb/in.2 \\
129 & 20 \\
160 & 50 \\
190 & 165 \\
220 & 320 \\
254 & 620 \\
283 & 1,010 \\
310 & 1,570 \\
327 & 2,020 \\
346 & 2,490 \\
\hline
\end{tabular}


If the data for the hydrochloric acid determinations, table 1, are plotted in the form of $\log _{10}$ of the pressure (abs) as a function of reciprocal absolute temperature, it can be noted that the three lines through the points representing temperatures from $200^{\circ}$ to $300^{\circ} \mathrm{C}$ (see fig. 10) nearly intersect in a point. For the purpose of

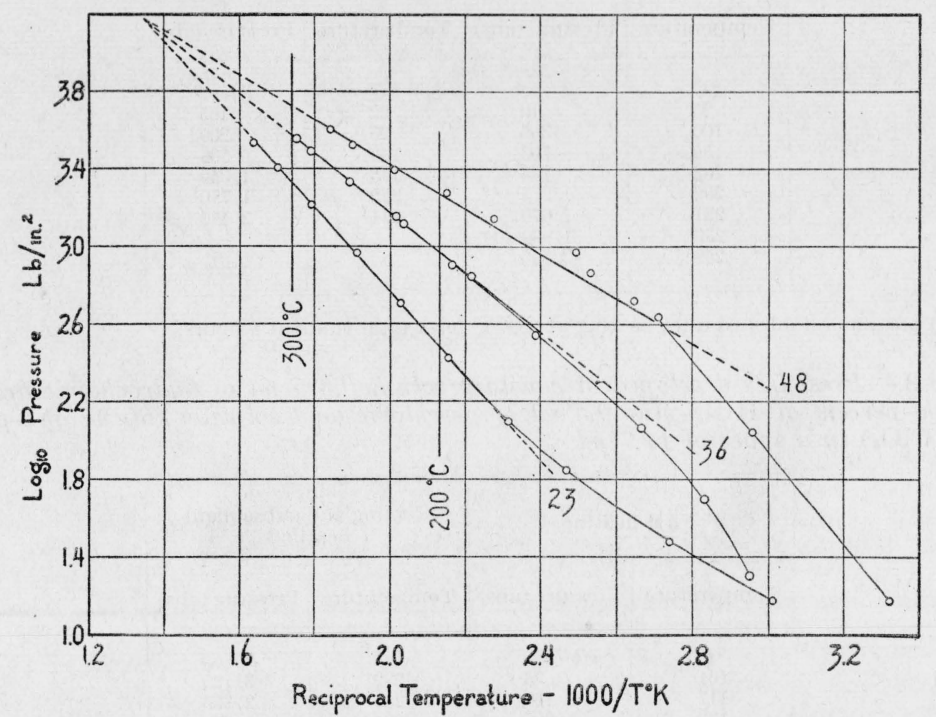

FIGURE 10.-Logarithm of pressure as a function of temperature for three strengths of hydrochloric acid.

predicting the pressure of an acid of any composition within the range 23 to 48 percent by weight, at temperatures between $200^{\circ}$ and $300^{\circ} \mathrm{C}$, these lines were forced to coincide at one point, and an equation of the pressure as a function of the temperature and of the composition was derived. The equation for the range 23 weightpercent to 48 weight-percent and $200^{\circ} \mathrm{C}$ to $300^{\circ} \mathrm{C}$, is

$$
\log _{10} P=\left(\frac{1000}{T}-1.345\right)[\tan (0.615 W+100.7)]+4.180,
$$

where $P$ is the pressure in $\mathrm{lb} /$ in. $^{2}$ attained at $T^{\circ} \mathrm{K}$ by a solution of $W$ weight-percent of $\mathrm{HCl}$ in a tube which is 43 percent filled by the acid at room temperature. The angle, of which the tangent is to be used in the equation, is here expressed as degrees.

Washington, May 25, 1944. 